\title{
Epidemiology of hip fracture and the development of FRAX in Ukraine
}

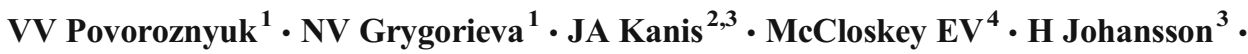

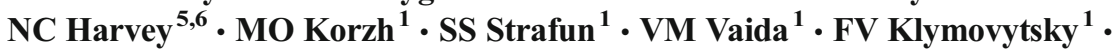 \\ RO Vlasenko ${ }^{1}$. VS Forosenko ${ }^{1}$
}

Received: 9 March 2017 / Accepted: 28 April 2017 / Published online: 31 May 2017

(C) The Author(s) 2017. This article is an open access publication

\begin{abstract}
Summary A country-specific FRAX model has been developed for the Ukraine to replace the Austrian model hitherto used. Comparison of the Austrian and Ukrainian models indicated that the former markedly overestimated fracture probability whilst correctly stratifying risk.

Introduction FRAX has been used to estimate osteoporotic fracture risk since 2009. Rather than using a surrogate model, the Austrian version of FRAX was adopted for clinical practice. Since then, data have become available on hip fracture incidence in the Ukraine.

Methods The incidence of hip fracture was computed from three regional estimates and used to construct a country-specific FRAX model for the Ukraine. The model characteristics were
\end{abstract}

VV Povoroznyuk

okfpodac@ukr.net

JA Kanis

w.j.Pontefract@shef.ac.uk

1 State Institution, D. F. Chebotarev Institute of Gerontology NAMS Ukraine, Ukrainian Scientific Medical Center of Osteoporosis, Kyiv, Ukraine

2 Centre for Metabolic Bone Diseases, University of Sheffield, S10 2RX, Sheffield, UK

3 Institute for Health and Aging, Catholic University of Australia, Melbourne, Australia

4 Centre for Integrated Research in Musculoskeletal Ageing (CIMA), Mellanby Centre for Bone Research, University of Sheffield, Sheffield, UK

5 MRC Lifecourse Epidemiology Unit, University of Southampton, Southampton SO16 6YD, UK

$6 \quad$ NIHR Southampton Biomedical Research Centre, University of Southampton and University Hospital Southampton NHS Foundation Trust, Tremona Road, Southampton, UK compared with those of the Austrian FRAX model, previously used in Ukraine by using all combinations of six risk factors and eight values of BMD (total number of combinations $=512$ ).

Results The relationship between the probabilities of a major fracture derived from the two versions of FRAX indicated a close correlation between the two estimates $(r>0.95)$. The Ukrainian version, however, gave markedly lower probabilities than the Austrian model at all ages. For a major osteoporotic fracture, the median probability was lower by $25 \%$ at age 50 years and the difference increased with age. At the age of 60,70 and 80 years, the median value was lower by 30,53 and $65 \%$, respectively. Similar findings were observed for men and for hip fracture.

Conclusion The Ukrainian FRAX model should enhance accuracy of determining fracture probability among the Ukrainian population and help to guide decisions about treatment. The study also indicates that the use of surrogate FRAX models or models from other countries, whilst correctly stratifying risk, may markedly over or underestimate the absolute fracture probability.

Keywords Epidemiology $\cdot$ Hip fractures $\cdot$ Ukraine $\cdot$ FRAX · Austria

\section{Introduction}

FRAX $®$ is a computer-based algorithm developed by the former World Health Organization Collaborating Centre for Metabolic Bone Diseases and first released in 2008. This algorithm calculates fracture probability from clinical risk factors in women and men $[1,2]$. The output of FRAX is the 10year probability of a major osteoporotic fracture (hip, clinical spine, humerus or wrist fracture) and the 10-year probability of hip fracture. Probability is calculated from age, body mass 
index (BMI) and dichotomized risk factors comprising prior fragility fracture, parental history of hip fracture, current tobacco smoking, long-term oral glucocorticoid use, rheumatoid arthritis, other causes of secondary osteoporosis and excessive alcohol consumption. Femoral neck BMD can be optionally input to enhance fracture risk prediction [3].

The risk of hip fracture and probably of other osteoporotic fractures varies significantly around the world [4]. The difference in incidence between countries is much greater than the difference in incidence between sexes within a country. Indeed, greater than tenfold differences in hip fracture incidence have been reported in different countries. For this reason, FRAX models are calibrated for each country dependent on the epidemiology of death and fracture (most usually hip fracture). To date, FRAX models are available for 63 countries (http://www.shef.ac.uk/FRAX) covering more than $80 \%$ of the world population [5].

All the required information to build a FRAX model is not available in all countries. In such cases, the use of a surrogate model has been proposed [6] using the death rate of the index country and the fracture rate of a country thought to be similar to the index country in terms of fracture risk. Examples include Sri Lanka, India [7, 8] and until recently, Armenia. The Ukrainian Scientific Medical Centre on Osteoporosis Problems (Kiev) has used FRAX to estimate the osteoporotic fracture risk since 2009 [9]. Rather than using a surrogate model, the Austrian version of FRAX was adopted for clinical practice [10]. Since then, data have become available on hip fracture incidence in the Ukraine. The aims of the present study were to develop the Ukrainian FRAX model according to the age- and sex-specific hip fracture rates in Ukraine and to compare this with the Austrian FRAX model currently recommended for Ukraine.

\section{Methods}

The development and validation of FRAX have been extensively described $[1,2]$. The risk factors used were based on a systematic series of meta-analyses of population based cohorts worldwide and validated in independent cohorts with over 1 million patient-years of follow-up. The construct of the FRAX model for Ukraine required the beta coefficients of risk factors in the original FRAX model, and the incidence of hip fracture and death for Ukraine. The death hazard for 2009 was taken from the data base of the United Nations [11].

\section{Cohorts}

The risk of hip fracture was calculated from two studies at three regional sites in Ukraine (Vinnitsa city (1997-2002), STOP-Study (Uzhgorod city and Vinnitsa area, 2011-2012). The results of these studies have been reported elsewhere [12,
13]. In brief, in the Vinnitsa city study, cases of hip fracture were identified retrospectively over a 6-year period (from 01.01.1997 to 31.12.2002) in men and women aged 50 years or more. The second study (Study of the prevalence of Osteoporotic fractures in Ukrainian Population-STOPStudy), organized by the Ukrainian Association of Osteoporosis, gathered retrospective information over 2 years (01.01.2011 to 31.12.2012) in two regions-Uzhhorod city and Vinnitsa area excluding Vinnitsa city.

\section{Ascertainment of incident fractures}

All data were retrieved from multiple sources (the records of the ambulance service, city and district hospitals and outpatient departments). All instances of double-counting corresponding to multiple admissions for the same fracture were deleted before analysis. Cases were defined as patients (aged 40 years or more) who were identified with hip fracture

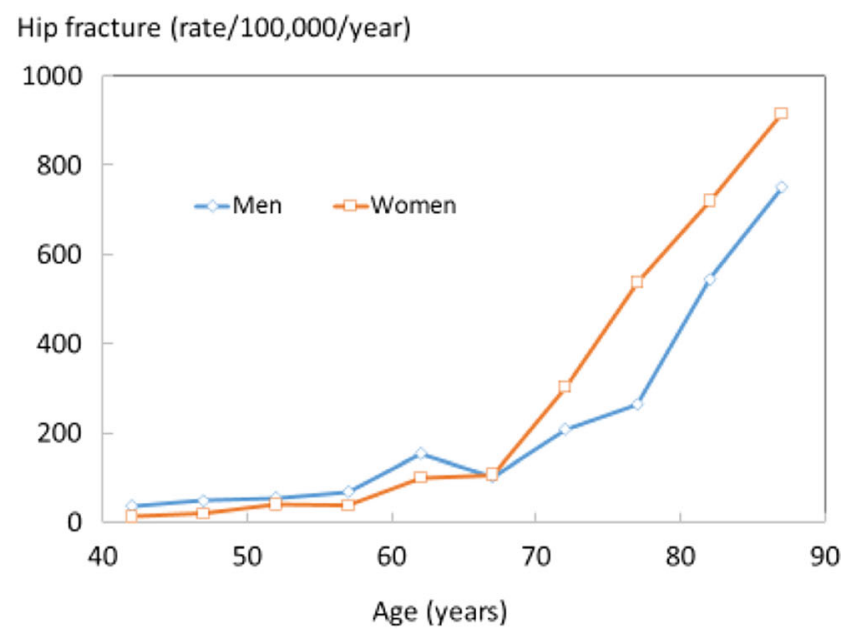

Hip fracture (rate/100,000/year)

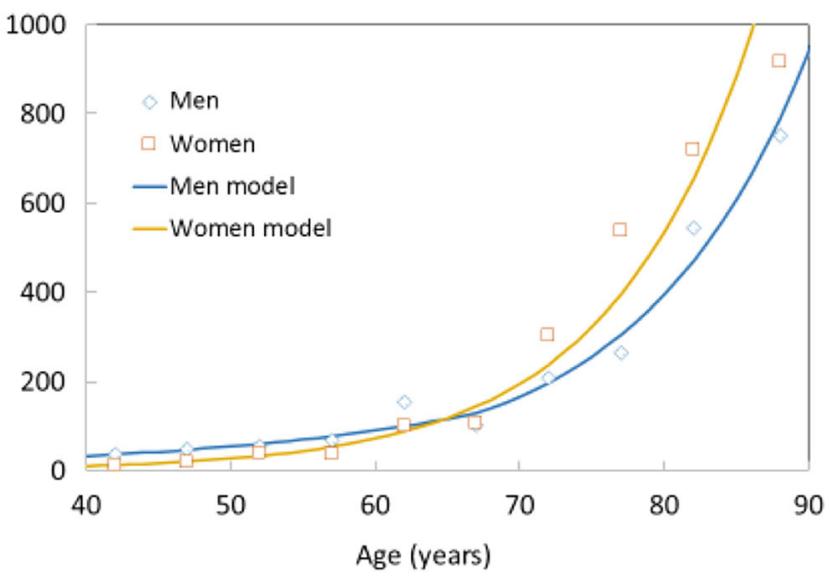

Fig. 1 Observed Ukrainian age- and gender-stratified incidence of hip fracture (upper panel) and comparison of observed data (symbols) and 1year incidence rates derived from piecewise linear regression (lower panel) 
Fig. 2 Comparison of 10-year probability of a major osteoporotic fracture using the Austrian FRAX tool applied to the Ukrainian female population and the Ukrainian tool for multiple clinical scenarios. The diagonal dashed line shows the line of identity
Probability Ukrainian model
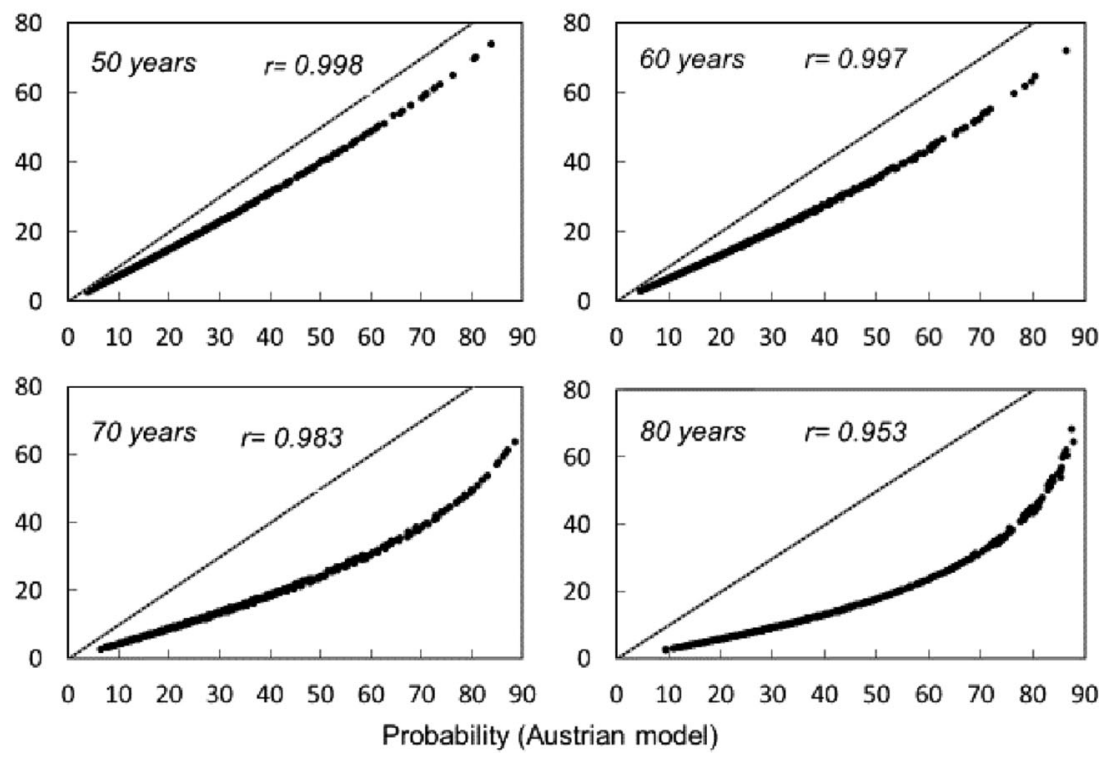

(ICD10 code S72.0 [femoral neck], S72.1 [trochanter], S72.2 [subtrochanter]) irrespective of the level of trauma, but cases associated with neoplasia were excluded. We excluded patients with a code S72.9 (unspecified site of femoral fracture) except where a surgical procedure indicated surgery on the hip. Patients who had sustained a hip fracture in the previous year at the same site were excluded as were patients with multiple admissions for the same fracture in the index year. We included patients with a hip fracture, who used the ambulance service but refused hospitalization and treatment later. We included hip fracture cases irrespective of region or country of origin.

Cases were ascertained from the age of 40 years since this is the lower age limit used in FRAX. Incidence rates were estimated as the number of men and women in 5-year age intervals with one hip fracture in the year divided by the age- and sex-specific population of each catchment using government estimates for the same year. Data from the three regional studies were amalgamated weighted by catchment population. For the purposes of FRAX, data were smoothed using piecewise linear regression on log-transformed incidence rates by age with a breakpoint at 67 years of age. Thereafter, the exponent was included in the FRAX model so that risk could be calculated at any specific age rather than in 5-year intervals.

\section{Comparison of Ukrainian and Austrian FRAX models}

For the purpose of comparing the Ukrainian and the Austrian models, probabilities of a major osteoporotic fracture (hip, clinical spine, forearm and humeral fractures) and of hip
Table 1 Probability (\%) of a major osteoporotic fracture (MOF) or a hip fracture (with 95\% tolerance intervals; TI) in women at the percentiles of the probability distribution (Austrian version) by age

\begin{tabular}{|c|c|c|c|c|c|c|c|}
\hline & \multicolumn{6}{|c|}{ Percentile } & \multirow[t]{3}{*}{$r$ value } \\
\hline & \multicolumn{2}{|l|}{10} & \multicolumn{2}{|l|}{50} & \multicolumn{2}{|l|}{90} & \\
\hline \multirow[t]{2}{*}{ Age } & Austria & Ukraine (95\% TI) & Austria & Ukraine $(95 \% \mathrm{TI})$ & Austria & Ukraine (95\% TI) & \\
\hline & \multicolumn{7}{|c|}{ MOF } \\
\hline 50 & 8 & $6(5-6)$ & 20 & $15(15-16)$ & 49 & $38(38-39)$ & 0.998 \\
\hline 60 & 10 & $6(6-7)$ & 23 & $16(15-16)$ & 51 & $36(35-36)$ & 0.997 \\
\hline 70 & 13 & $5(4-6)$ & 30 & $14(13-15)$ & 65 & $35(33-36)$ & 0.983 \\
\hline \multirow[t]{2}{*}{80} & 19 & $5(4-7)$ & 43 & $15(13-16)$ & 76 & $40(38-42)$ & 0.953 \\
\hline & & & & Hip & & & \\
\hline 50 & 0.4 & $0.2(0.0-0.5)$ & 4 & $3(3-3)$ & 31 & $24(24-25)$ & 0.999 \\
\hline 60 & 0.7 & $0.3(0.0-0.7)$ & 5 & $3(3-4)$ & 29 & $19(19-20)$ & 0.999 \\
\hline 70 & 2.3 & $0.6(0.0-1.5)$ & 12 & $5(4-6)$ & 51 & $24(23-4)$ & 0.987 \\
\hline 80 & 6.3 & $1.4(0.0-2.9)$ & 28 & $9(7-11)$ & 71 & $32(30-34)$ & 0.956 \\
\hline
\end{tabular}


Table 2 Probability (\%) of a major osteoporotic fracture (MOF) or a hip fracture (with $95 \%$ tolerance intervals; $\mathrm{TI})$ in men at the percentiles of the probability distribution (Austrian version) by age

\begin{tabular}{|c|c|c|c|c|c|c|c|}
\hline \multirow[t]{3}{*}{ Age } & \multicolumn{6}{|c|}{ Percentile } & \multirow[t]{3}{*}{$r$ value } \\
\hline & \multicolumn{2}{|l|}{10} & \multicolumn{2}{|l|}{50} & \multicolumn{2}{|l|}{90} & \\
\hline & Austria & Ukraine (95\% TI) & Austria & Ukraine (95\% TI) & Austria & Ukraine (95\% TI) & \\
\hline \multicolumn{8}{|c|}{ MOF } \\
\hline 50 & 7 & $4(3-6)$ & 19 & $12(11-14)$ & 53 & $36(34-37)$ & 0.997 \\
\hline 60 & 8 & $4(3-5)$ & 19 & $11(10-12)$ & 46 & $26(25-27)$ & 0.996 \\
\hline 70 & 9 & $3(2-4)$ & 22 & $9(8-9)$ & 49 & $22(21-22)$ & 0.988 \\
\hline 80 & 12 & $3(2-4)$ & 28 & $9(8-10)$ & 57 & $24(23-25)$ & 0.975 \\
\hline \multicolumn{8}{|c|}{ Hip } \\
\hline 50 & 0.7 & $0.3(0.0-1.2)$ & 6 & $4(3-5)$ & 40 & $26(25-27)$ & 0.998 \\
\hline 60 & 1.1 & $0.5(0.0-1.1)$ & 6 & $3(2-4)$ & 31 & $17(16-17)$ & 0.997 \\
\hline 70 & 2.6 & $0.6(0.0-1.5)$ & 12 & $5(4-6)$ & 42 & $18(17-19)$ & 0.989 \\
\hline 80 & 5.7 & $0.9(0.0-2.1)$ & 21 & $7(5-8)$ & 54 & $21(20-22)$ & 0.975 \\
\hline
\end{tabular}

fracture alone, were computed in men and women at ages 50, 60,70 and 80 years for all possible combinations of clinical risk factors at BMD T-scores between 0 and $-3.5 \mathrm{SD}$ in 0.5 $\mathrm{SD}$ steps with a BMI set to $25 \mathrm{~kg} / \mathrm{m}^{2}$ [14]. Thus, we considered all combinations of six risk factors and eight values of BMD giving a total number of combinations of 512 . Note that this was not a population simulation, but an array of all possible combinations. The correlation between the Austrian and Ukrainian fracture probabilities was examined by piecewise linear regression with knots at probabilities of 50 and $70 \%$ for the Austrian probabilities of a major osteoporotic fracture and at 5 and $20 \%$ for hip fracture using the same model. The reason for using knots at different probabilities for the two outcomes was because of the difference in the distribution of probabilities. Tabular data compared probabilities with the two versions at the 10th, 50th (median) and 90th percentile of the distribution of the Austrian model. Differences in the

Table 3 Ten-year probability of major osteoporotic fracture (MOF) and hip fracture in men and women aged 65 years with a prior fragility fracture. (Body mass index set to $25 \mathrm{~g} / \mathrm{m}^{2}$ )

\begin{tabular}{lllll}
\hline Country & $\begin{array}{l}\text { Men } \\
\text { MOF }\end{array}$ & Hip fracture & $\begin{array}{l}\text { Women } \\
\text { MOF }\end{array}$ & Hip fracture \\
\hline Austria & 9.7 & 2.5 & 17 & 4.3 \\
Belarus & 3.1 & 0.9 & 6.2 & 1.8 \\
Hungary & 6.2 & 1.6 & 12 & 3.1 \\
Moldova & 9.3 & 2.5 & 17 & 4.7 \\
Poland & 4.5 & 1.2 & 8.3 & 2.2 \\
Romania & 5.2 & 1.5 & 9.5 & 2.6 \\
Russia & 9.2 & 1.3 & 18 & 2.6 \\
Slovakia & 9.1 & 2.4 & 17 & 4.3 \\
Ukraine & 4.6 & 1.2 & 8.8 & 2.3 \\
\hline
\end{tabular}

Ukrainian version at these percentiles were expressed as $95 \%$ tolerance intervals (TI).

In order to compare Ukrainian hip fracture probabilities with adjacent countries with a FRAX model and Austria, the remaining lifetime probability of hip fracture and major osteoporotic fracture from the age of 50 years was calculated for men and women, as described by Kanis et al. [15, 16].

\section{Results}

Figure 1 shows 1-year age- and gender-stratified incidence rates of hip fracture for the Ukraine from the three regional studies, as well as the incidence of hip fractures, based on the linear regression. Hip fracture incidence was lowest in patients aged 40-54 years and increased progressively with age. Below the age of 65 years, hip fracture incidence was higher in men than in women but, above this age the incidence increased more markedly in women compared to men.

\section{Fracture probability}

The relationship between the probabilities of a major fracture derived from the two versions of FRAX is shown for women aged 50 to 80 years in Fig. 2. At all ages, there was a close correlation between the two estimates $(r>0.95)$. The Ukrainian version gave lower probabilities than the Austrian model at all ages. The median value was lower by $25 \%$ at the age 50 years and the difference increased with age. At the age of 60,70 and 80 years, the median value was lower by 30,53 and $65 \%$, respectively. 
In the case of hip fracture, there was also a close correlation between the two estimates $(r>0.95)$ at all ages. The Ukrainian version gave lower estimates than the Austrian model at all ages and by a proportion that increased with age (Table 1). In men, the effect of the revision was qualitatively similar to that in women (Table 2).

The large disparities between Austrian and Ukrainian models were reflected in differences in the lifetime probabilities of a hip fracture from the age of 50 years. In Austria, this was $19.6 \%$ in women and $8.2 \%$ in men. The equivalent probabilities in Ukraine were 5.4 and $2.8 \%$, respectively.

\section{Discussion}

In this study, we documented the incidence of hip fracture in the Ukraine. The incidence of hip fracture was used to populate a country-specific FRAX tool to compute the 10-year probabilities of hip and major osteoporotic fracture. The new model can now replace the Austrian model used since 2009. In brief, the Ukrainian model provided substantially lower estimates of fracture probability at all ages. Importantly, the country-specific model had little impact on the categorization of risk, since the revisions did not change the rank order of fracture probability. In the clinical scenarios presented in this paper, the correlation coefficients between the Austrian and authentic versions for fracture probability exceeded 0.95 at all ages and in men as well as women. Thus, an individual at the 90th percentile of risk with the Austrian tool would still be very close to the 90th percentile of risk using the Ukrainian FRAX tool. For this reason, the consequences of using country-specific tools reside in the absolute number generated and not in the rank order of risk. The same phenomenon has been observed in FRAX revisions [14]. This is of little consequence to the management of patients or the interpretation of clinical studies. There is a useful analogy with the different DXA devices available, where a substantial difference in femoral neck BMD is seen between Hologic and Lunar machines, but the T-score derived from these is more or less identical [17]. However, difficulties arise when fracture probabilities are used in health economic analysis to inform practice guidelines or devise intervention thresholds.

It is evident that the use of the Austrian model grossly overestimated FRAX probabilities in Ukraine. Where FRAX models are not available for a specific country, the International Society for Clinical Densitometry and International Osteoporosis Foundation recommend the use of surrogate FRAX models using the fracture risk of a neighbouring country together with the death risk of the index country [6]. Ukraine, situated in Eastern Europe, shares borders with the Russian Federation to the east and north-east, and with Belarus towards the north-west border. Hungary, Slovakia and Poland are to its west; Romania and Moldova share its south-west border. A comparison of probabilities of the Ukrainian model with the Austrian model is given in Table 3 together with neighbouring counties. The probabilities were lower than in neighbouring countries with Poland being the closest. In view of the disparate results, the adoption of a surrogate country (rather than the entire Austrian model) might have given equally misleading results.

Ideally, FRAX models should use fracture rates for the whole country [4], whereas the present study sampled fracture rates from three regions (two of 24 provinces) representing only about $1 \%$ of the total population aged 40 years or more. It is well established that there are regional variations in hip fracture rates within countries [18-21]. Indeed, regional differences in hip fracture incidence have been reported using common methodology with the higher rates in urban communities in several countries [20-24] but, given the absence of national registers, we had to rely on the regional estimates. The situation is not unique and regional estimates have also been used to create FRAX models for Brazil [25-30].

A limitation of the present study is that we were not able to collect data on fracture at sites other than the hip. For this reason, the FRAX model relied on hip fracture rates to estimate the incidence of a major osteoporotic fracture. For this purpose, it is assumed that the ratio of hip fracture incidence to other FRAX outcomes (clinical spine, distal forearm and proximal humerus) is the same in the index country as that documented in Sweden. The ratios for Sweden were derived using national hip fracture data for Sweden and data from Malmo for the other fracture outcomes [31]. Despite many studies that have examined the incidence of fractures by age and sex, there are problems in defining the pattern of fractures in different countries. The available evidence indicates that the incidence of major fractures can be reasonably predicted from the incidence of hip fracture [31-33].

With these caveats, a country-specific FRAX model has been developed for the Ukraine which can now replace the Austrian model hitherto used. This model should enhance accuracy of determining fracture probability among the Ukrainian population and help to guide decisions about treatment. The study also indicates that the use of surrogate FRAX models or models from other countries, whilst correctly stratifying risk, may markedly over or underestimate the absolute fracture probability.

Acknowledgments We are grateful for the collaboration of the group of hospitals that provided the data for this study.

\section{Compliance with ethical standards}

Competing interests Professor Kanis led the team that developed FRAX as director of the former WHO Collaborating Centre for Metabolic Bone Diseases; he has no financial interest in FRAX. Professors McCloskey, Oden, Harvey and Dr. Johansson are members of the FRAX team. Professors Harvey, Kanis and McCloskey are members of the Expert Advisory Group of the National Osteoporosis Guideline Group, UK. The other authors have disclosed no conflicts of interest.

Open Access This article is distributed under the terms of the Creative Commons Attribution 4.0 International License (http:// 
creativecommons.org/licenses/by/4.0/), which permits unrestricted use, distribution, and reproduction in any medium, provided you give appropriate credit to the original author(s) and the source, provide a link to the Creative Commons license, and indicate if changes were made.

\section{References}

1. Kanis JA, on behalf of the World Health Organization Scientific Group (2008a) Assessment of osteoporosis at the primary healthcare level. WHO Collaborating Centre, University of Sheffield, UK, Technical report

2. Kanis JA, Johnell O, Oden A, Johansson H, McCloskey E (2008b) FRAX $^{\mathrm{TM}}$ and the assessment of fracture probability in men and women from the UK. Osteoporos Int 19:385-397

3. Kanis JA, Oden A, Johnell O et al (2007) The use of clinical risk factors enhances the performance of BMD in the prediction of hip and osteoporotic fractures in men and women. Osteoporos Int 18:1033-1046

4. Kanis JA, Oden A, McCloskey EV, Johansson HD, Wahl A, Cooper C (2012) A systematic review of hip fracture incidence and probability of fracture worldwide. Osteoporos Int 23(9):2239-2256

5. Kanis JA, Harvey NC, Cooper C, Johansson H, Odén A, McCloskey EV, the Advisory Board of the National Osteoporosis Guideline Group (2016) A systematic review of intervention thresholds based on FRAX. Arch Osteoporos 11(1):25

6. Kanis JA, Hans D, Cooper C, Baim S, Bilezikian JP, Binkley N, Compston J, Dawson-Hughes B, El-Hajj Fuleihan G, Johansson H, Leslie WD, Lewiecki EM, Luckey MM, Oden A, Papapoulos SE, Poiana C, Wahl DA, Mc Closkey E, and the Task Force of the FRAX Initiative (2011) Interpretation and use of FRAX in clinical practice. Osteoporos Int 22:395-411

7. Kanis JA (2013) Commentary on guidelines on postmenopausal osteoporosis - Indian Menopause Society. J Midlife Health 4:129-131

8. Lekamwasam S (2013) Sri Lankan FRAX model and countryspecific intervention thresholds. Arch Osteoporos 8:148

9. Povoroznyuk VV, Grygorieva NV (2011) Role of FRAX in predicting the risk of fracture. Medicine and Pharmacy News 16: 379 [Article in Russian] http://www.mif-ua.com/archive/article/ 21687 Accessed 4th December 2016

10. Povoroznyuk VV, Grygorieva NV (2013) Evaluation of the possibilities of using the Austrian model of FRAX in predicting the risk of osteoporotic fractures among Ukrainian women. Pain Joints Spine 3: 11 [Article in Russian] http://www.mif-ua.com/archive/ article/37586 Accessed 4th Dec 2016

11. United Nations (2015) World Population Prospects 2015. Available at https://esa.un.org/unpd/wpp/ Accessed 17 Jan 2017

12. Povoroznyuk VV, Grygorieva NV, Korzh MO, Strafun SS, Vaida VM, Klymovytsky FV, Vlasenko RO, Forosenko VS, Kanis JA, Johansson H, McCloskey EV (2016) Epidemiology of the proximal femur fractures in Ukraine: results of stop-study (System of Registration of Osteoporotic fractures in Ukrainian Population). Trauma [Ukrainian] 3:14-20

13. Povoroznyuk VV, Grygorieva NV, Korzh MO, Strafun SS, Kanis JA, Johansson H, McCloskey EV, Vaida VM, Klymovytsky FV, Vlasenko RO, Forosenko VS (2016) Epidemiology of proximal femur fractures in Ukraine: results of two retrospective studies. Orthopedics, traumatology and prosthetics [Ukrainian] 4:68-74

14. Kanis JA, Johansson H, Oden A, Dawson-Hughes B, Melton LJ 3rd, McCloskey EV (2010) The effects of a FRAX((R)) revision for the USA. Osteoporos Int 21:35-40

15. Kanis JA, Johnell O, Oden A, Sembo I, Redlund-Johnell I, Dawson A, De Laet C, Jonsson B (2000) Long-term risk of osteoporotic fracture in Malmö. Osteoporos Int 11(8):669-674

16. Kanis JA, Odén A, Mc Closkey EV, Johansson H, Wahl DA, Cooper $\mathrm{C}$, and on behalf of the IOF Working Group on
Epidemiology and Quality of Life (2012) A systematic review of hip fracture incidence and probability of fracture worldwide. Osteoporos Int 23(9):2239-2256. doi:10.1007/s00198-012-1964-3

17. Binkley N, Kiebzak GM, Lewiecki EM, Krueger D, Gangnon RE, Miller PD, Shepherd JA, Drezner MK (2005) Recalculation of the NHANES database SD improves T-score agreement and reduces osteoporosis prevalence. J Bone Miner Res 20(2):195-201

18. Johnell O, Gullberg B, Allender A, Kanis JA, and the MEDOS Study Group (1992) The apparent incidence of hip fracture in Europe. Osteoporos Int 2:298-302

19. Benetou V, Orfanos P, Feskanich D, Michaëlsson K, PetterssonKymmer U, Ahmed LA (2015) Education, marital status, and risk of hip fractures in older men and women: the CHANCES project. Osteoporos Int 26(6):1733-1746

20. Emaus N, Olsen LR, Ahmed LA et al (2011) Hip fractures in a city in Northern Norway over 15 years: time trends, seasonal variation and mortality: the Harstad Injury Prevention Study. Osteoporos Int 22:2603-2610

21. Elffors L, Allander E, Kanis JA, Gullberg B, Johnell O, Dequeker J, Dilzen G, Gennari C, Lopez-Vaz AA, Lyritis G, Mazzuoli GF, Miravet L, Passeri M, Perez Cano R, Rapado A, Ribot C (1994) The variable incidence of hip fracture in southern Europe. The MEDOS Study. Osteoporos Int 4:253-263

22. Morosano M, Masoni A, Sánchez A (2005) Incidence of hip fractures in the city of Rosario. Argentina: Osteoporos Int 16:1339-1344

23. Odén A, Kanis JA, McCloskey EV, Johansson H (2014) The effect of latitude on the risk and seasonal variation in hip fracture in Sweden. J Bone Miner Res 29:2217-2223

24. Matković V, Kostial K, Simonović I, Buzina R, Brodarec A, Nordin BE (1979) Bone status and fracture rates in two regions of Yugoslavia. Am J Clin Nutr 32:540-549

25. Zerbini CA, Szejnfeld VL, Abergaria BH, McCloskey EV, Johansson H, Kanis JA (2015) Incidence of hip fracture in Brazil and the development of a FRAX model. Arch Osteoporos 10:224

26. Karacić TP, Kopjar B (2009) Hip fracture incidence in Croatia in patients aged 65 years and more. Lijec Vjesn 131(1-2):9-13

27. Lyritis GP, Rizou S, Galanos A, Makras P (2013) Incidence of hip fractures in Greece during a 30-year period: 1977-2007. Osteoporos Int: May 24(5):1579-1585

28. Azagra R, Zwart M, Encabo G, Aguyé A, Martin-Sánchez JC, PucholRuiz N, Gabriel-Escoda P, Ortiz-Alinque S, Gené E, Iglesias M, Moriña D, Diaz-Herrera MA, Utzet M, Manresa JM, GROIMAP study group (2016) Rationale of the Spanish FRAX model in decisionmaking for predicting osteoporotic fractures: an update of FRIDEX cohort of Spanish women. BMC Musculoskelet Disord 17:262

29. Lesnyak O, Ershova O, Belova K, Gladkova E, Sinitsina E, Ganert O, Romanova M, Khodirev V, McCloskey JE, Kanis J (2012) Epidemiology of fracture in the Russian Federation and the development of a FRAX model. Arch Osteoporos 7:67-73

30. Czerwinski E, Kanis JA, Osieleniec J, Kumorek A, Milert A, Johansson H, McCloskey EV, Gorkiewicz M (2011) Evaluation of FRAX to characterise fracture risk in Poland. Osteoporos Int 22:2507-2512

31. Kanis JA, Oden A, Johnell O, Jonsson B, de Laet C, Dawson A (2001) The burden of osteoporotic fractures: a method for setting intervention thresholds. Osteoporos Int 12:417-427

32. Lam A, Leslie WD, Lix LM, Yogendran M, Morin SN, Majumdar SR (2014) Major osteoporotic to hip fracture ratios in Canadian men and women with Swedish comparisons: a population-based analysis. J Bone Miner Res 29(5):1067-1073

33. Siggeirsdottir K, Aspelund T, Johansson H, Gudmundsson EF, Mogensen B, Jonsson BY, Gudnason V, McCloskey E, Oden A, Sigurdsson G, Kanis JA (2014) The incidence of a first major osteoporotic fracture in Iceland and implications for FRAX. Osteoporos Int 25:2445-2451 